\title{
Ferrihydrite Transformation Rate Modeling and its Mechanism in the Presence of Adsorbed Oxyanions
}

\author{
ALIREZA NAMAYANDEH, F.MARC MICHEL ${ }^{*}$ \\ Virginia Tech, Department of Geosciences, Blacksburg, VA \\ 24060, USA (*correspondence: mfrede2@vt.edu) \\ Ferrihydrite (Fh) is a metastable iron hydroxide \\ nanoparticle that, under oxic conditions, eventually \\ transforms to less hydrated and more stable iron (hydr)oxides \\ such as goethite (Gt) and hematite (Hm). These minerals are \\ by far the dominant iron oxides in the surface environment, \\ and due to their high specific surface area and high reactive \\ surface sites readily make complexes with ion species such as \\ oxyanions and control their cycling and behavior in soil and \\ groundwater. We have developed a kinetic model that \\ describes and predicts the effect of different types of surface \\ complexation, from weak electrostatic outer-sphere for $\mathrm{NO}_{3}^{-}$, \\ to a mix of outer-sphere and inner-sphere for $\mathrm{SO}_{4}{ }^{2-}$, to \\ predominantly strong bidentate inner-sphere for $\mathrm{H}_{2} \mathrm{AsO}_{4}{ }^{-}$, on \\ the mechanism of Fh transformation. Two sets of pure and \\ adsorbed $\mathrm{Fh}$ samples were prepared, non-buffered and \\ buffered at $\mathrm{pH} 5.5 \pm 0.2$, aged for up to 50 days at $70 \pm$ \\ $1.5^{\circ} \mathrm{C}$, and then characterized using synchrotron $\mathrm{x}$-ray total \\ scattering and linear combination fitting (LCF) to identify \\ phases and quantify phase abundances, respectively. The \\ kinetic model showed that the rate of $\mathrm{Fh}$ transformation is not \\ constant in the presence of $\mathrm{NO}_{3}{ }^{-}$and $\mathrm{SO}_{4}{ }^{2-}$ such that the rate \\ is slower at the beginning of the transformation where \\ oxyanions are present on the surface before desorbing to the \\ solution. Both buffered and non-buffered As-adsorbed \\ samples were stable, with only $<2 \%$ transformed during 50 \\ days of aging, suggesting a negative correlation between the \\ rate of transformation and strength of the oxyanions bonding \\ on the Fh surface. Also, results showed that the rate constant \\ of transformation is almost twice in the non-buffered pure \\ sample, showing the importance of constant $\mathrm{pH}$ in measuring \\ the rate of Fh transformation.
}

